\title{
Coyuntura económica de El Salvador 1992
}

\author{
Joaquín Arriola
}

El Salvador, además de su peculiar coyunlura política e histórica, es un caso muy interesante desde el punto de vista económico. Por tercer año, un gobierno conservador, extremadamente ideologizado en lo económico, se aplica a implementar un programa de ajusle estructural y un programa de eslabilización de corte (teóricamente) muy ortodoxo, neoliberal. Sin embargo, El Salvador tiene la característica que lo diferencia de los demás paises que aplican programas neoliberales: la resIricción externa no exisle. En efeclo: los programas neoliberales en América Latina se han generalizado bajo la presión de la deuda externa, por tanlo de la limilación en el acceso a divisas para enfrentar sus obligaciones externas, lo cual genera un contexlo de debilidad para negociar con los acreedores y sus técnicos (FMI, BID y Banco Mundial).

Pero en El Salvador, desde hace unos afios, las remesas de los emigranles sobre todo de Estados Unidos, donde vive aproximadamente el $20 \%$ de la población total del pais, representan ya un volumen superior a todas las exportaciones. Si a esto le anadimos una cuantiosa ayuda externa, el país se puede permilir unos déficils de balanza comercial, es decir, unos desequilibrios macroeconómicos, que están evilando el enorme coste social que el programa neoliberal tiene en el resto del continente. Es decir, en El Salvador se está aplicando una prolunda "reforma estruclural" neoliberal (ya se ha cubierto más del $80 \%$ del programa de ajusle estrutural), sin que la población tenga que sulrir el impacto de las medidas de estabilización fondomonelaristas, que suele preceder en otros paises a la aplicación de la reforma bancomundialista. 
Los indicadores de utilización de la capacidad muestran en 1992 una mejoría, lo cual signilica una mejora en la lasa de ganancia. Mejora de la rentabilidad del capital que, como se verá por los indicadores macroeconómicos, entre los que destaca la acentuación del deterioro de los desequilibrios presupuestario y de comercio externo, y el fracaso de la reforma fiscal, apuntan a una quiebra profunda del modelo.

La consecuencia es evidente: en un contexto privilegiado, de estabilización sin austeridad (o de imporlantes desequilibrios, pero sostenibles) y por tanto de ajuste estruclural sin coste social, la estrategia quiebra precisamente por las caracteristicas estructurales que contribuye a acentuar: la dependencia del ahorro externo, el carácter profinanciero y anliproductivo, la preponderancia de la burguesia compradora y del capilal rentista trente al capital productivo.

\section{La coyuntura macroeconómica}

Las variables macroeconómicas más importantes son la inversión en bienes de capilal (medida por la formación bruta de capital tijo, FBCF) y la variación en el número de asalariados y de las rentas salariales.

La inversión lo es por dos razones: en primer lugar es el componente del producto que presenla mayores márgenes de variación en función de la coyuntura, siendo por tanto el principal indicador que modifica la tasa de crecimiento y la principal senal de la tendencia de la coyuntura, y en segundo lugar, porque es el único componenle del producto que garanliza la proyección del crecimiento de la coyuntura hacia el mediano y largo plazo, es decir, es lo que podríamos llamar "estabilizador del crecimiento".

El empleo y las rentas salariales tienen una importancia fundamental en los paises de la región centroamericana ya que, debido a su bajo nivel en general, presenlan dentro del consumo privado una propensión marginal al consumo de mercancias de origen doméstico más elevada que las otras rentas (las ganancias especialmente, porque las rentas campesinas representan una proporción menos signiticativa dentro del consumo tolal, aunque puedan presenlar una propension al consumo doméstico aun mayor que los salarios). Dicho de otro modo, el consumo basado en las rentas salariales tiene un efecto estabilizador que no posee el consumo basado en las otras rentas (salvo las renlas campesinas).

Por tanlo, un crecimiento del consumo basado en las rentas salariales, sobre todo si es el resultado de una expansión del número de empleos más que de un aumento de los niveles salariales, garantiza unas 
expectalivas empresariales mejores y por tanto un crecimiento sostenido en la producción doméstica.

\subsection{La Inversión}

La FBCF (indicador relativo de la inversión en bienes de equipo: nuevo y de reposición) es pues el indicador fundamental de la acumulación o el crecimiento sostenible, es decir, apoyado en los factores internos de la economia.

Un rápido análisis de la inversión en los paises que han experimentado largos periodos de crecimiento y de transformación estructural (los paises desarrollados en los ańos 50 y 60 , los países de industrialización acelerada en los ańos 60 y 70 en Asia y Latinoamérica), nos permile afirmar que el nivel mínimo de FBCF que se requiere para un crecimiento soslenible con Iransformación producliva se sitúa, dependiendo de la composición del capital, de su edad y del ciclo lecnológico, entre un $20 \%$ y un $30 \%$ del PIB.

En El Salvador, desde 1970 , solo en los años $1975-78$ se alcanzó un nivel de inversión que se siluaba en el mínimo para hablar de crecimiento internamente sostenible. El resto de los ańos en las dos décadas pasadas, los niveles de inversión lanto pública como privada no permiten un desarrollo de las fuerzas productivas, y en algunas ocasiones, difícilmente permiten la simple reposición del capilal (que no aparece como una restricción muy fuerte por los bajos niveles de utilización de la capacidad inslalada): entre 1970-89, la relación I/PIB se siluó en un $14.2 \%$, siendo un $9.9 \%$ la inversión privada, y un $4.7 \%$ la pública.

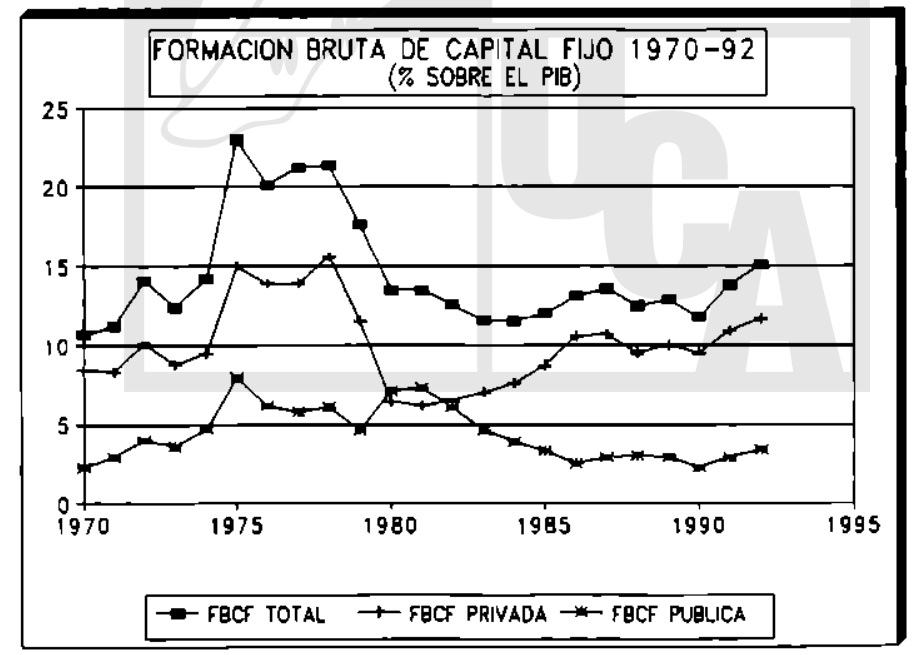


La gestión neoliberal no ha sido capaz de modificar la lendencia estructural a la subinversión, ya que la FBCF solo representó un $11.8 \%$ y un $13.8 \%$ del PIB en 1990 y 1991, mientras que en 1992, se ha observado una mayor utilización de la capacidad instalada, consecuencia del incremento de la demanda de consumo, pero sin que ello se haya traducido en un aumento signilicativo de la inversión a medio y largo plazo.

Es decir: a pesar de estar prácticamente implementada la reforma estructural neoliberal, a pesar de que el capital ha recuperado el control del sistema político y de los principales mecanismos de captación del excedenle (sistema financiero y de exportación), y pese a una demanda privada de consumo superior al nivel de desarrollo y de utilización de las fuerzas productivas, que genera expectativas empresariales muy favorables, el capital no invierte en generar capacidad productiva nueva. Por tanto, esa demanda privada, ese consumo basado en las transferencias unilaterales de capital (ayuda internacional y ayuda familiar), está siendo convertida por el capital en ganancia comercial, en ganancia rentista, pero no en olerla productiva.

Y esta va a ser la característica fundamental del modelo, que podemos calificar, en palabras de Peter Marchelli, de "estrategia de generación de ahorro externo". Lo significativo es que el ajuste neoliberal tiende a exacerbar estas caracleristicas renlistas del patrón de acumulación, aun aquí, donde la "sobrelinancialización" de la economia no está siendo exigida por el servicio de la deuda externa, por la restricción exlerna.

\subsection{El empleo}

El empleo rural de temporada ha conlinuado su disminución, hasta situarse por debajo del $20 \%$ de la PEA agrícola, según estimaciones preliminares, Irente al $60 \%$ que se enrolaba a principios de los 80 en las actividades agrícolas de exportación. La población ocupada en la lemporada actual se ha siluado en torno a las 230.000 personas.

Aunque el GOES atirma que en 1992 se han creado 19.400 empleos en las áreas rurales y urbanas pobres, la carencia de esladisticas en materia de empleo es absoluta. Por tanto, las afirmaciones sobre su evolución tienen que ser indirectas, pero todo apunla a que el año pasado aumentó el empleo urbano, por una parte como consecuencia inevilable del crecimienlo del PIB. Pero también se deduce de algunos indica dores indirectos, como es las ofertas de trabajo doméstico en el área metropolitana: a principios de afio, las otertas de trabajo eran por unos salarios de 300-350 colones, mientras que a finales de afio, los salarios 
de las empleadas domésticas se han elevado a los 400-450 colones, síntoma de escasez de demanda de trabajo en el sector.

\subsection{Los salarios}

Los salarios industriales y de servicios de la fuerza de trabajo no cualificada o poco cualificada (nivel máximo de bachillerato) fluctúan entre el mínimo de 600 colones en las zonas urbanas departamentales y el de 850 colones en la zona melropolitana de San Salvador, y los 1.500 colones, con una reducida proporción de los trabajadores ganando hasta 2.500 colones, y una mayoría de asalariados (fundamentalmente empleadas domésticas, asalariados rurales y asalariados del sector iniormal), ganando por debajo del minimo legal (con salarios que fluctúan entre 250 y 500 colones.

En agosto se dio un decreto de moditicación de salarios mínimos, que elevó el salario minimo en el área metropolitana de 23.5 hasta 27.5 colones diarios, y de 22.5 a 26.5 colones en otros municipios. Pero este aumento tue absorbido exclusivamenle por el alza de precios del periodo septiembre-diciembre. El aumento del $15 \%$ de los salarios desapareció en términos reales con el alza de precios del $16 \%$ en el último cuatrimestre. Hay que senalar que los salarios de cosecha no se han modilicado desde 1990 (19.5 colones/día en el café y 16.2 colones en la cańa y 14.5 en el algodón), compensando el aumento de la tasa de explolación la caida de los excedentes empresariales en los cultivos de exportación. Si sabemos que en torno a un cuarto de millón de trabajadores dependen de los salarios de temporada para su acceso a los bienes de consumo mercantiles, se deduce que su capacidad adquisitiva se ha reducido considerablemente en los últimos afios.

Por tanlo el deterioro de los salarios reales ha sido muy elevado en el año 1992, (con excepción del servicio doméstico) deterioro que de ningún modo ha podido ser compensado con el incremento en el volumen de empleo, lo cual nos lleva a pensar que la participación de los salarios en el PIB se han reducido aun más desde la implantación de la política neoliberal de ARENA.

\subsection{La producción}

El crecimiento del PIB en los últimos años se ha basado esencialmenle en la demanda de consumo. El consumo privado representó en 1991 el $87.5 \%$ del PIB, y el consumo público el $11 \%$ mientras que la inversión solo representó el $13.8 \%$. La evolución en 1992, con un incremento del $4.6 \%$ en el PIB, pero un aumento del $14.7 \%$ en las importaciones, por una reducción del $0.7 \%$ en las exporlaciones, un incremento 
del $11.8 \%$ en las remesas, y un aumento de la inversión pública de un $41.3 \%$, nos indica claramente que el aumento del PIB se basa en un nuevo tirón de la demanda de consumo, a partir del incremento de las remesas y del gasto público asociado a los programas de compensación $y$ de reconstrucción nacional.

La economía salvadoreña vive una profunda crisis productiva o de oferta, disimulada detrás de la demanda generada con el uso de los recursos externos. Así, la grave crisis agropecuaria, tanto en precios inlernacionales como en producción de granos básicos, no se traslada a la ciudad, que vive de los factores externos.

El crecimiento de la producción agropecuaria en 1992 no es un indicador de buena salud del seclor, porque obedece a factores coyunturales (compensación por la mala cosecha del año pasado debida a la sequía, aumento de la superticie cullivada en 45.000 manzanas, por las condiciones de paz del país): entre 1989 y 1992, la producción agricola solo ha aumentado un $3.6 \%$ del año, porcenlaje que, considerado la expansión demográfica y del suelo cullivado, representa una evolución negativa de la productividad agrícola.

El sector más dinámico en los últimos afios es la construcción (10.1\% y $12 \%$ de crecimiento en 1991 y 1992), lo cual indica de nuevo el peso delerminante de las remesas y la ayuda en la economia del pais: expansión de zonas comerciales y residencias de 25-30.000 dólares, y de residencias populares de 8-10.000 dólares, subsidiadas por la AID y olras agencias de cooperación.

De rebole, la expansión de la actividad industrial se centra en las industrias alimentarias, bebidas y tabaco, y en las suministradoras de insumos para la construcción.

Tasa de crecimiento de los componentes del PIB (\%)

\begin{tabular}{|lrrrr|}
\hline & 1989 & 1990 & 1991 & 1992 \\
\hline PIB & 1.1 & 3.4 & 3.5 & 4.6 \\
Agropecuario & 0.5 & 7.4 & -0.1 & 6.7 \\
Industria & 2.5 & 3.0 & 4.9 & 6.0 \\
Construcción & 3.6 & -12.8 & 10.1 & 12.0 \\
Comercio & 3.4 & 3.1 & 4.2 & 4.2 \\
Servicios personales & 1.5 & 1.8 & 3.8 & 3.8 \\
\hline
\end{tabular}

Fuente: GOES, Miplan 
Significativamente, la actividad más dinámica en los últimos anos, pero que suele estar excluida de las cilras oficiales, por no formar parte de la economía nacional en su senlido pleno, es la actividad de la maquila. Solo en la Zona franca de San Bartolo (única en operación, con 14 empresas), las "exportaciones" (y por lando la producción, pues toda producción es exportada en las zonas francas) sobrepasan los 75 millones de dólares, con una lasa de crecimiento anual de la producción total de la zona desde 1977 del $18.8 \%$, y un aumenlo de las exportaciones por empresa del $10.8 \%$ anual entre 1977 y 1990 . A eslas 14 plantas de exporlación hay que agregarle las más de 120 fábricas maquiladoras que poseen estaluto de recinto fiscal en el país (es decir, de producción integramente para la exportación), en más de un $80 \%$ pertenecienles al sector de la confección. Este lenómeno es un auténlico proceso de pérdida de cultura industrial, por cuanto muchas de eslas maquiladoras son antiguas industrias textiles nacionales, ahora reconvertidas en plantas de ensamblaje subcontratadas

En definitiva, el crecimienlo del PIB no se debe a un proceso dinámico de desarrollo de las fuerzas produclivas, sino a faclores externos que tornan al crecimiento de la economia sumamente vulnerable a lactores incontrolables, como el clima y las transterencias unilaterales.

\subsection{El sector exterlor}

\subsubsection{La balanza comerclal}

La característica más significativa de la balanza comercial, desde 1990, es la tendencia acelerada al incremenlo del délicit. Esto es resultado, por una parte, del deterioro de los lérminos de inlercambio para el café, que conlinúa siendo el motor de las exportaciones: $45 \%$ de los ingresos por exporlaciones en 1990, 38\% en 1991.

Por otro lado, las imporlaciones están creciendo a un rilmo muy acelerado, aproximadamente unos 200 millones de dólares al ano, desde 1989. Los crecimientos más especlaculares se han producido en los bienes de consumo duradero: (el material de transporte pasó de ser el $7.4 \%$ de las imporlaciones tolales en 1990 a más del $12 \%$ en 1992, los aparalos eléctricos, han pasado en dos años del $4 \%$ de las importaciones a cerca del $7 \%$ ), y los alimentos (del $6.5 \%$ al $10 \%$ ) especialmente el trigo, que como consecuencia del cambio en la dieta alimentaria, ha pasado en dos años del $1.1 \%$ de las importaciones al 3.5\%. Los abonos también han multiplicado por cuatro su peso en las importaciones (el $0.4 \%$ al $1.6 \%$ ), consecuencia de la finalización de la guerra y la ampliación de la superticie de cultivo. 
Como consecuencia, en 1992 se ha tenido un déficit comercial de unos 1092 millones de dólares. Los ingresos por exporlaciones, que serán este año inferiores a los de 1988, mientras que las importaciones habrán aumentado más de un $60 \%$ respecto a aquel ano.

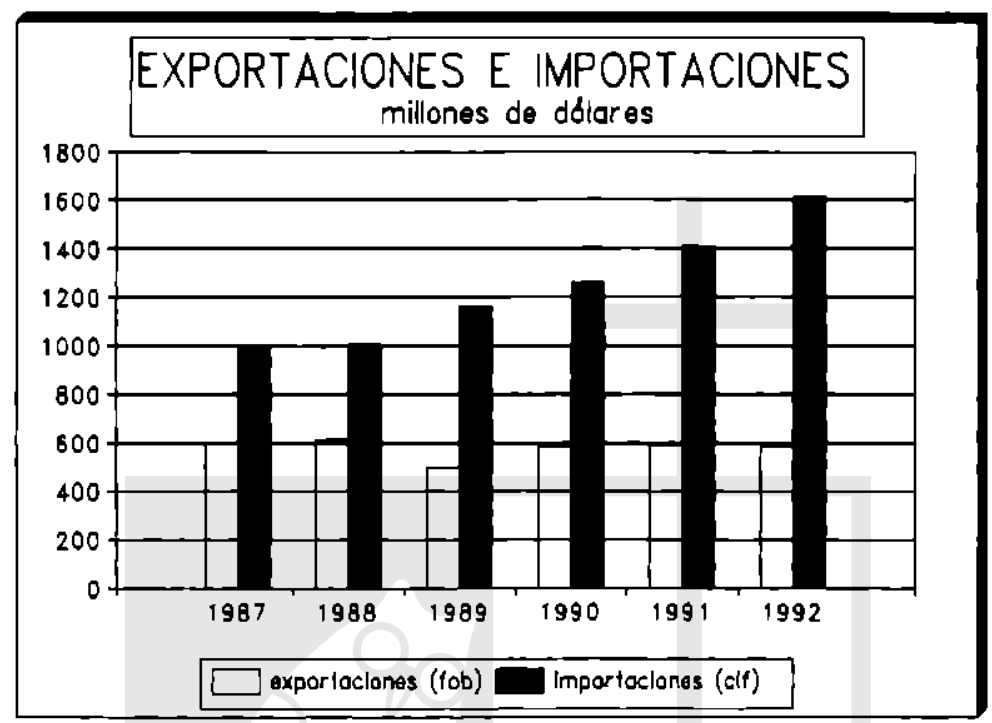

\subsubsection{La balanza por cuenta corrlente}

La mala situación de la balanza por cuenla corriente, además de por el serio delerioro de la balanza comercial se ve agravado por la repatriación de utilidades de las empresas multinacionales, que alcanza la clfra de 150 millones de dólares (142,7 millones en 1990), con un déficit en el capítulo de unos 125 millones al ano, desde la llegada de Arena al gobierno, un incremento de unos 10 millones respecto a la siluación en los anos inmediatamente anteriores.

En los anos 80 el déficit de la balanza por cuenta corriente era compensada por las transferencias unilaterales, que aun en 1988 daba un saldo de balanza por cuenta corrienle posilivo en 25 millones de dólares. Una característica del actual periodo de gobierno es haber deleriorado la siluación a lal punto que el saldo se ha vuello negativo: -184 millones en 1989, -135 millones en 1990 y -118 millones en 1991. El saldo negativo de la balanza por cuenta corriente ha disminuido todavia en 1992, gracias a la conlribución de la ayuda internacional. 


\subsubsection{Las remesas}

Las remesas de emigrantes, que en 1992 alcanzaron los 718 millones de dólares, se ha convertido en el factor estabilizador de la balanza por cuenta corriente más importante a medio plazo. Las remesas representan cerca del $7 \%$ del PIB, y si en 1991 representaron el $67 \%$ de las exportaciones, en 1992 alcanzaron el 123\% de las exportaciones.

Ciertamente las remesas juegan un papel económico que va más allá de la simple contabilidad externa: son la principal inyección de tondos en el consumo de los trabajadores, por cuanto una estimación grosera del volumen de los salarios, nos hace pensar que estos representan entre 650 y 700 millones de dólares. Por tanto las remesas práclicamente duplican la capacidad adquisitiva de los trabajadores en su conjunto, especialmenle de los seclores de bajos ingresos: el $61 \%$ de las familias receptoras de remesas tienen unos ingresos mensuales interiores a 2.000 colones, y el $38 \%$ inferiores a 1.000 colones mensuales ..:

- Las remesas están contribuyendo a un acelerado cambio en los patrones de consumo (los rubros de importación más dinámicos son el trigo, aparalos electrodomésticos y los vehículos automóviles, las cadenas de hamburguesas se han multiplicado de forma impresionante en los últimos tres ańos), y a un aumento de la urbanización, lo mismo que a un proceso de desculluralización creciente (es sintomático el cambio en los usos de vestuario de la población, cada vez más asimilados a los estilos de los emigrantes en L.A., $O$ el auge de la música rock de origen norteamericano incluso en zonas rurales).

\subsubsection{La situación general de balanza de pagos}

La balanza de pagos no se presenta como una reslricción de corto plazo a la política neoliberal y sus resultados, porque el deterioro comercial es compensado por las transferencias unilalerales (ayuda $y$ remesas). Pero el agravamiento de la balanza comercial ha sido tan acentuado en los últimos Ires anos, que el gobierno ha tenido que acudir al endeudamiento externo (más de 200 millones de dólares en 1991) para compensar vía balanza de capitales el saldo de la balanza de pagos global.

Las medidas de fomento de repalriación de capilales por la via de mejorar la renlabilidad de los depósilos bancarios, se ha mostrado como una política extremadamente volátil: si los pasivos bancarios a largo plazo representaron unas entradas 115 y de 106 millones de dólares en 1989 y 1990 (frente a solo 7 millones en 1987-88), en 1991 las salidas fueron de 169 millones, con to cual el saldo de los tres anos se sitúa en 
unos escasos 18 millones de dólares, a lalta de información sobre el saldo correspondienle a 1992.

En definitiva, la siluación descrita augura que el déficit externo será una de las cargas y restricciones más importantes que se legará al próximo gobierno que surja tras las elecciones de 1994, y es la demosIración del fracaso de la estrategia neoliberal de fomento de exportaciones, incapaz modificar estructuralmenle la debilidad extema de la economia salvadorefía.

\subsection{La slluación monetaria}

EI BCR implementó en noviembre unas medidas de drenaje de liquidez del sistema financiero que fueron duramenle contestadas por los gremios empresariales. El argumento del organismo gubernamental se basó en considerar que la economía estaba sufriendo un exceso de liquidez, como consecuencia de la financiación de la expansión del gasto público orientado a cumplir los acuerdos de paz y el programa de reconstrucción, y que ese exceso de liquidez estaba favoreciendo la especulación cambiaria.

En realidad como se puede observar en el siguienle grálico, los datos to que muestran es un especlacular crecimiento de los depósitos bancarios, desde la llegada de Arena al gobierno, tendencia que se acelera en 1992, sin que el crédito siga un crecimiento paralelo. Además, el crecimiento del crédito se debió casi lodo a créditos para consumo, especialmente el crédito al seclor público que es el que más ha crecido en los anos de gestión de Arena, y crédito al consumo, gaslado en la adquisición de viviendas y bienes de consumo duradero importados (especialmente automóviles), lo cual conlribuyó suslanlivamente al delerioro de la balanza comercial sefnalado más arriba.

Por tanto, lo que cabe deducir es que la situación finarıciera del sistema bancario se deterioró signiticativamente en el ano 1992, ante un enorme crecimienlo del pasivo sin posibilidades correlativas de incremenlo del activo. $Y$ esta siluación resullaba políticamente inaceptable al gobierno, recién cumplido el proceso de privatización bancaria.

La especulación contra la divisa que también se dio en el último Irimestre del año se debió más bien el control oligopólico de las casas de cambio por parte de miembros del grupo económico linanciero de Cristiani, que acapararon las divisas con objelo de elevar el tipo de cambio y oblener una ganancia especulativa, evitando al mismo tiempo que la entrada pasiva de dólares en ocasión de las fiestas navidenas signiticase una reducción del tipo de cambio por debajo del precio pagado en los meses previos por la divisa estadounidense. 


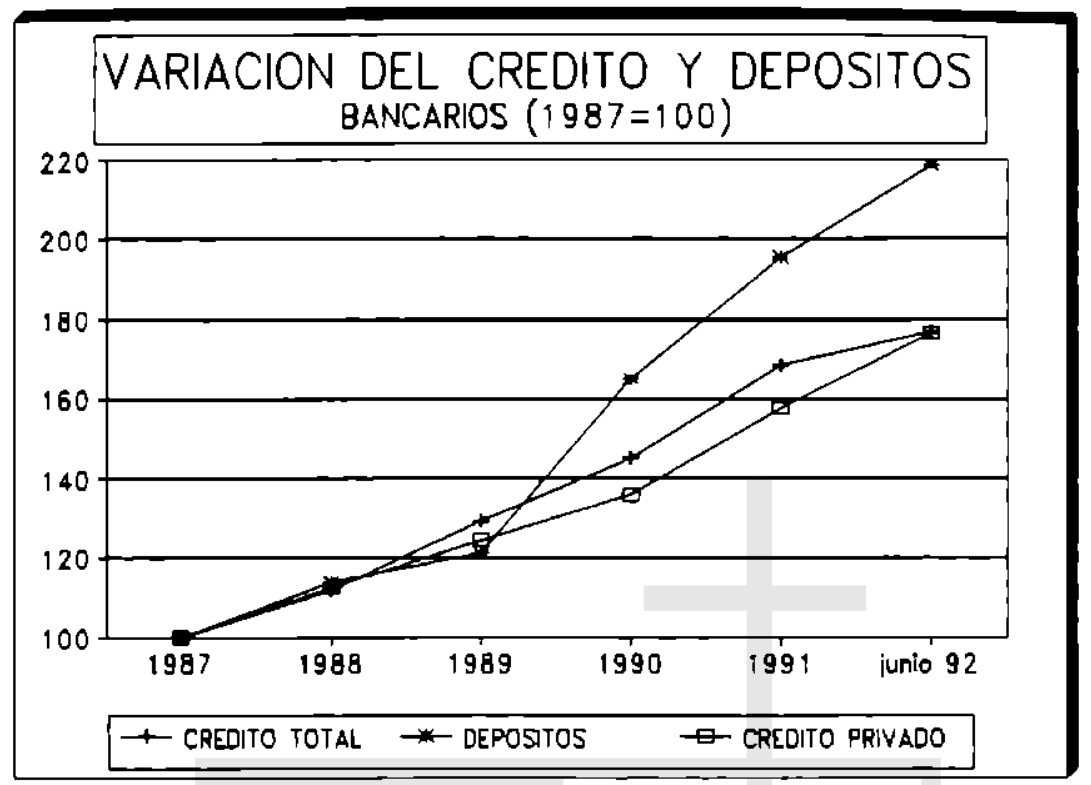

Resolver esta situación le costó al BCR (presidido por otro miembro del grupo Cristiani, Roberto Orellana Milla, y que cuenta como entre sus directores propietarios a Ricardo Hill, y entre sus asesores a Roberto Llach Hill) unos $\mathbf{5 0}$ millones de dólares, que fueron lanzados al mercado es decir, a las casas de cambio controladas por el mismo grupo económico- para frenar el delerioro del lipo de cambio.

El año 1992 lerminó con un congelamiento de todas las líneas de crédito en el sistema bancario, con excepción del crédilo agrícola y las líneas de crédito para la micro y pequefa empresa.

Las medidas de reducción de liquidez parecen más orientadas, en la perspectiva monelarista del gobierno, a provocar una reducción de la masa monelaria con el objetivo de reducir el consumo, como mecanismo para reducir el aumento disparado de la inflación a partir de septiembre, con lasas superiores al $4 \%$ mensual, e intentar frenar la tendencia al aumento del déficit comercial.

\subsection{Otros desequilibrlos financleros}

\subsubsection{Inflación}

En electo: las previsiones del GOES a finales de 1991, de lograr un 
aumento de los precios en el año recien terminado inferior al $8.5 \%$, se han visto truncadas por el espectacular incremento de los precios en el último cuatrimeslre del año, aumento vinculado a la especulación comercial en torno a la aplicación del IVA, y a las alzas de los costes de producción derivada de los aumenlos en los precios de los servicios básicos, la gasolina y el transporte, aplicados lambién a partir de sepliembre. Como resultado de esta siluación, el índice de precios refleja una variación anual superior al $23 \%$, superior en $7-9$ punlos a la que existía al finalizar la década de los 80 .

\subsubsection{Déficit fiscal}

Uno de los resultados más perniciosos de la política del aclual gobiemo es su incapacidad para controlar el déficit público, que alcanzó en el af́o recién lerminado los 1918 millones de colones. El deterioro de las tinanzas públicas ha llegado al punlo que el ahorro corriente muestra una tendencia negaliva, más acusada en los últimos tres ańos que en cualquier período de los últimos tres lustros, como se puede comprobar en el gráfico siguiente.

El desahorro del gobierno central, que se habia controlado en los últimos años de la década pasada, hasta obtener valores positivos en 1988 ( $1.4 \%$ del PIB), se deleriora aceleradamente con el gobierno de

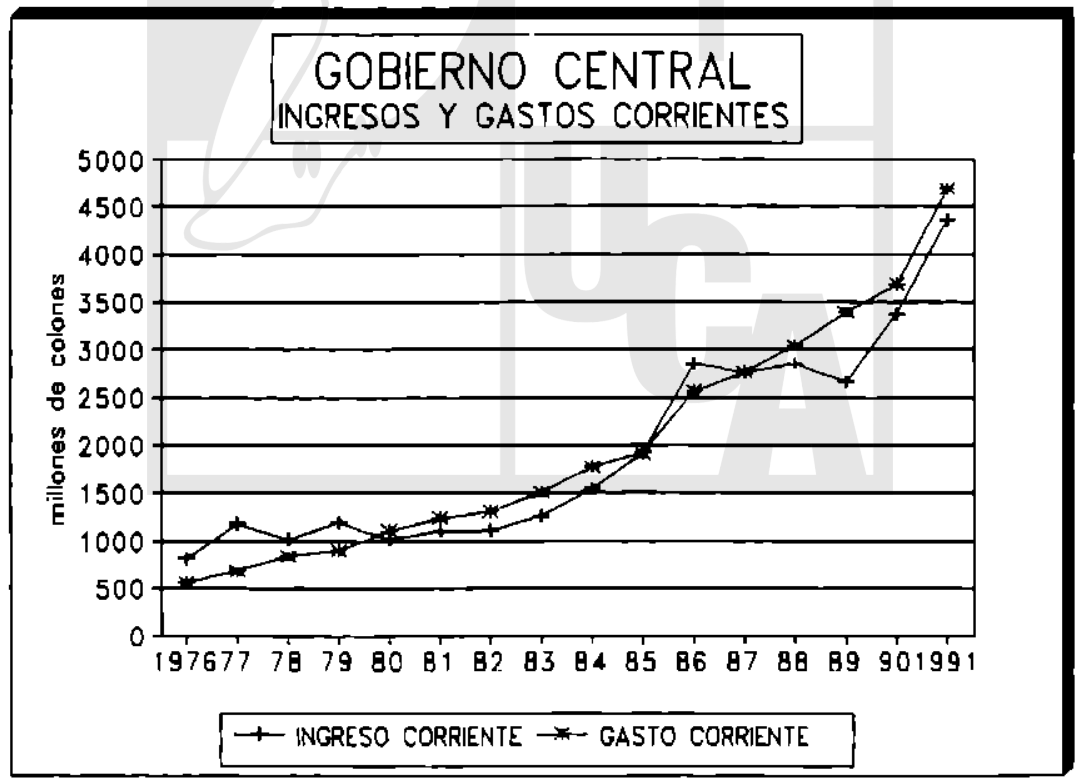


Arena, cuyo desahorro representa el $2.3 \%$ del PIB en $1989,0.8 \%$ en 1990 y $0.7 \%$ en 1991.

La siluación es aun más grave si se considera el superávit o déficil financiero global, del gobierno central, que habiéndose mantenido en torno a los 300 millones de colones desde 1986, se dispara en 1989 hasta los 1050 millones de colones. Desde 1989 las utilidades de las empresas públicas autónomas se reducen a cero, con lo cual el estado consolidado de las cuenlas del seclor público, tradicionalmente aliviadas por los resullados de las autónomas, se agravan aun más respecto a los resullados particulares del gobierno central.

En el período enero-junio de 1992 el ahorro corriente ha sido solo el $41 \%$ del obtenido en igual período de 1991 , con lo cual, previsiblemente el resultado a final de año haya sido un deterioro sustancial de las cuentas del sector público, pues el déficit tinanciero global, excluidas donaciones, habia aumentado en el período sefialado un $125 \%$ respecto a igual periodo del ańo anlerior.

La incapacidad política del GOES para elevar suslancialmenle la recaudación fiscal, es la principal causa del desequilibrio financiero, que en cualquier caso se presenta como menos grave que el desequilibrio exlerno, y más dependiente de variables políticas (voluntad y capacidad de elevar la reducida recaudación tributaria), que económicas.

\subsubsection{Deuda externa}

La deuda externa pasó de 2.73 millones de dólares en 1991 a 2.76 millones en 1992: un incremento del $9.8 \%$, muy por encima del $4.6 \%$ de crecimiento del PIB, lo cual habla de un deterioro en materia de endeudamiento externo en el año recien finalizado. La deuda externa actual representa casi cuatro años de exportaciones, y alcanza el $38.2 \%$ del PIB.

La voluntad manifestada por el gobierno de cubrir el déficit fiscal acudiendo al endeudamienlo externo aumentará aun más el nivel de la deuda externa, pero resulla coherente con la situación relativa de las diferentes áreas: acudir al mercado inlerno para linanciar el déficit fiscal, tendría que hacerse elevando las tasas de interés y forzando una recesión, mientras que la situación de balanza de pagos, por la via de las translerencias unilaterales (donaciones y remesas) permile garantizar en el corto plazo una situación de credibilidad ante los financiadores externos. El anuncio del gobierno norleamericano de que condonaría 464 millones de dólares de la deuda bilateral de El Salvador con los EE.UU. (un tercio del total), como "regalo" por la finalización del conflicto armado, refuerza esta orienlación. 


\section{Politica de ajuste estructural}

El esludio de la lógica social de las políticas de ajuste estructural (PAE) se suele dejar fuera de los análisis tecnocrálicos dominantes. Hay que entender que el PAE es una Estrategia anticrisis, que parte de un diagnostico y propone un renıedio que responden a una óptica de clase especílica:

El diagnóstico considera al estado y a los trabajadores como los responsables de la crisis económica. En la visión neoliberal, los trabajadores, con su poder dentro de las empresas, redujeron el crecimiento de la productividad hasta el punto de que los incrementos salariales fueron mayores que los de produclividad a principios de los '70. Además, con su poder en la sociedad, lograron, con el apoyo de políticos populistas que solo pensaban en los volos, unos gastos sociales por parte del Estado que lo llevó a la crisis fiscal.

El objelivo de la estrategia en incrementar la tasa de ganancias del capital, y para ello se proponen dos medidas: reducir el Estado "económico" y reducir el poder de los trabajadores. Y de paso, ante la "irresponsabilidad" de políticos y trabajadores, incremenlar el poder de los capitalistas, los únicos que piensan.en la ganancia, que es el único criterio de valor en una economia mercantil.

Las actividades del Estado susceptibles de ser objeto de valorización por el capital privado, serán objelo de privatización, y las no valorizables, serán recortadas, reduciendo asi tanto los ingresos (de las empresas públicas) como los gastos (de inversión y sociales).

El poder de los trabajadores se reducen dentro de las empresas, con el aumenlo del desempleo a partir de la aulomatización creciente de los procesos, y el alaque a la organización sindical. Su poder social se reduce, logrando medianle la conveniente campańa de manipulación ideológica a gran escala, un aumento del individualismo y de las actiludes favorables a los partidos conservadores.

\subsection{Polílica comerclal}

Desde un principio, el gobierno de Arena adoptó una rápida reducción arancelaria. En el primer mes de gobierno se redujo el lecho del $290 \%$ al $50 \%$ y se elevó al piso del $0 \%$ al $5 \%$, las calegorias arancelarias se redujeron de 25 a 7 . En 1992 se redujo el lecho al $20 \%$, pero el piso no se ha elevado, pese a las reiteradas demandas en ese sentido del BID y el Banco Mundial.

Los aranceles a la exportación han desaparecido, con la reforma que se introdujo al impuesto sobre el calé. 
Con la úllima reforma de este impuesto decrelada por Arena, en octubre de 1991, por los primeros 45 dólares el quintal no se paga impues1o, y por encima de ese precio, se pagan 30 centavos por cada dólar. En 1992 el precio cayó por debajo de los 60 dólares el quinlal. Con lo cual, el impuesto:

$$
60-45=15 \times 30 \%=4.5
$$

se redujo a casi nada, ante la caída del volumen lísico exporlado por la decisión de los exportadores de acumular inventarios a la espera de una mejora en el precio internacional del café.

Si a esto se le af́ade el fondo de estabilización 45 millones de dólares aprobado por la Asamblea Legislativa, para que los caletaleros hagan frenle a la deuda bancaria (evitando una nueva mora en el sistema financiero recien privatizado) y al pago a los beneficiadores (que acaparan junto a exporladores la parte más sustancial del excedente), se comprueba una vez más el peso de la oligarquía tradicional en el aparato político (pensemos que a los cañeros, constituidos en gran medida por cooperalivas se les calificó por voceros del gobierno como "agiladores políticos" cuando pedian un tratamiento más venlajosos en maleria de precios de inlervención).

\subsection{Privatización}

Con la privatización de tres bancos casi se ha completado la privalización de la banca, que fuera disefiada y decidida en el domicilio el Presidente de la República, en un esquema de reparto de los activos entre los principales grupos económicos del pais.

La privatización de los activos más apelecidos por el capital transnacional (telecomunicaciones y energía) se está implementando, en el primer caso, sin clara conciencia por parte de los seclores populares, por la vía de la concesión de permisos (comunicaciones internacionales) a diversas multinacionales (MSI, ATT) y de los contratos de compras. En el caso de la energia, la estruclura de precios todavia nos hace completamente rentable desde el punto de vista financiero el servicio, aunque está prevista la privatización de la producción de energía en determinadas áreas del país y de las agencias distribuidoras.

\subsection{El fracaso de la reforma flscal}

Uno de los componentes esenciales de las políticas de ajuste eslruclural es la reforma fiscal. La Reforma Fiscal no se puede interpretar 
tomando cada impuesto de forma aislada, ni siquiera analizando todo el sistema imposilivo como un conjunto cerrado, pues la reforma de los ingresos eslá intimamente coneclada con la reforma del gasio: son parte del mismo paquele, cuya lógica solo se puede entender viendo ambas caras de la reforma.

El tratamiento de la cuestión fiscal en los paises desarrollados no es ajena a estos cambios sociales y políticos. Entre los anos 1975 y 1981. la concepción dominanle entre los economistas va a modificarse profundamente. Anles de esa fecha, en un período de crecimiento más o menos estable, el aumenlo del gasto público, dedicado a crear infraestructuras y gasto social, se veía como positivo, lavorecedor de las condiciones de valorización del capital privado. A partir de 1975, el crecimiento se reduce, y el Eslado se dedica cada vez más a gaslos improductivos: pago de pensiones y subsidios a los desempleados y a actividades produclivas como las comunicaciones, que se vuelven un objetivo tentador para el capital privado, necesitando de nuevos espacios de valorización ante la crisis de muchas aclividades tradicionales (siderurgia, construcción naval, automovil, elc.).

Esta nueva situación significará un cambio en la lógica fiscal: los impuestos direclos, que antes se veian como favorecedores de la redistribución de la riqueza, ceden terreno, y ahora se consideran desalenladores para la inversión y el crecimiento. Los impuestos indirectos sobre todo los impuestos al consumo se verán ahora más positivamente porque se considera que inciden menos negativamente sobre el ahorro y la inversión.

En América Latina, una diferencia estructural con los países desarrollados viene dada por el menor peso económico y social relativo de los trabajadores asalariados y de los capitalistas privados. En consecuencia, el PAE aplicado en Latinoamérica considera que el origen de lodos los males se encuentra en el Estado, en tanto esle ha jugado en las décadas pasadas un papel de "suplencia" frente al capilal, y las polílicas públicas han determinado el palrón de acumulación de un modo más determinanle que en los paises desarrollados.

Además, los agentes internacionales tienen un papel preponderante tanlo en la orientación como en la implementación de los PAE en América Latina: los organismos multilalerales de financiación (especialmente FMI. Banco Mundial y BID) se convierten en diseñadores de la política económica en sustitución de los gobiernos, y las mullinacionales -públicas y privadas - presionan por la privatización del patrimonio social y empresarial de los Eslados. 
EI IVA es el impueslo ideal para la lógica del ajuste: impuesto al consumo, que no pagan las empresas sino los ciudadanos consumidores, y cuya recaudación facilita el control fiscal de las actividades económicas (el Eslado neoliberalizado es mucho más controlador que el anlerior).

La reforma fiscal que se ha llevado a cabo en El Salvador es la aplicación directa, sin adaplación a las condiciones reales del país, de la políica liscal neoliberal. Los problemas fiscales del pais derivan de una escasa carga Iribularia, una elevada evasión, un excesivo peso de los impuestos indirectos, y el reducido número de contribuyentes potenciales directos. Para eslos problemas, no hay análisis ni respueslas, teóricas ni práclicas, en los documentos del gobierno, de Arena o de la AID.

EI IVA es generalmente un impuesto que se aplica para pasar de una esinuctura impositiva centrada en la renta a una centrada fundamentalmente en el consumo. Pero el impuesto que viene a sustituir -el Timbre - ya era un impuesto al consumo. Como el consumo constiluye una base fiscal más reducida que la renta, es evidente que los actuales gobernantes del pais no están pensando en resolver los problemas reales de la estructura Iributaria salvadoreña. La óplica de clase con la que se está realizando la reforma fiscal responde a los intereses de los seclores dominantes del gran capital. Además de la implantación del IVA, el gobiemo no ha realizado otras medidas de gran importancia: se han reducido a menos de la mitad las lasas impositivas en el impuesto de la renta, especialmenle las de las personas con elevados ingresos. A las personas juridicas (impuesto de sociedades), se ha reducido la tasa para aquellas empresas de más de 900.000 colones, y se ha elevado la tasa a las empresas con una cifra de negocios inferior a esa cantidad. Es decir, se han reducido las lasas a 330 grandes empresas, y a cambio se le han incremenlado a 9000 medianas y pequefias empresas. Además, el GOES cedió a las presiones del gran capital, y no aprobó la inclusión en el código penal del delito fiscal.

La lectura más inmediata que se deduce de lo anterior, en coherencia con la orientación prooligárquica del GOES, es que este espera incrementar la recaudación fiscal a través del IVA a partir de la fiscalización de las medianas y grandes empresas, pero que esle mayor control no significará una mayor recaudación del impuesto a la renta de las personas físicas y jurídicas aplicado a las grandes fortunas, pues el mayor control se compensa con la enorme reducción de las tasas. Aun asi se facilita siempre la evasión al no existir el delilo fiscal. Lo único que se le va a pedir a las empresas, por tanto, es que recauden el IVA - que no pagan ellas, sino los consumidores. 
La reforma liscal contribuirá a incrementar los ingresos fiscales del Estado, pero siempre en una medida insuficiente para lo requerido por una política de desarrollo efectivo. La estructura fiscal, que responde a un diseño coherentemente capitalista de la política fiscal, no va a reducir en absoluto la incoherencia económica y social. Cuando solamente el $40 \%$ de la riqueza nacional corresponde a los trabajadores asalariados, frente a un $60 \%$ de rentas no salariales (30\% de utilidades), la estructura fiscal, si descansa sobre el consumo, retringe la base fiscal a poco más de la milad de la riqueza nacional, quedando casi el $50 \%$ del PIB fuera del alcance del fisco (pues las renlas que se Iransforman en consumo son las salariales, y las no salariales en gran medida se ahorran, se invierlen o se consumen en el ex(erior).

El incremento de los precios experimentado en los últimos meses del año es principalmente consecuencia de los empresarios distribuidores, que lograron una ganancia especulativa incrementando los precios. cuando teóricamente el impacto marginal del IVA sobre los costes iba a ser mínimo, cuando no negalivo. La decisión del BCR de retirar liquidez del sistema, es una medida propia de la ortodoxia neoliberal para reducir el incremento de los precios, pero el coste que lleva aparejado en términos de fomentar la recesión será mucho mayor que el beneficio de contención de los incrementos de precios, pues el origen de la aceleración de la inflación no se encuentra en un exceso de liquidez, sino en el elevado grado de colusión presente en los mercados de bienes y servicios, en el control oligopólico de los precios por parte de los oferentes.

La reforma fiscal ha sido por lanto un rolundo fracaso, al reducir los ingresos por impuestos directos y por los impuestos sobre el comercio exterior, al seguir facilitando un elevadisimo fraude liscal, $y$ al haber implantado un impuesto que, al no haber actuado previamente sobre las estructuras distributivas, ha contribuido a borrar el único logro en maleria de búsqueda de equilibrios que habia logrado hasta ahora el programa neoliberal, que era el control de la inflación. Cuando el ciclo de las políticas noeliberales se está cerrando en lodo el mundo (tanto el gobiemo conservador británico, como el nuevo presidenle de los EE.UU., como la agencia olicial de cooperación japonesa... es a muy diversos niveles institucionales que se propone de nuevo polílica de incremento del gasto público y políticas secloriales de fomento) en EI Salvador, la irresponsable contrarretorma fiscal obliga a disenar un presupuesto para el ano '93 con profundas características contractivas, to cual dificulta la transición desde una situación de guerra a una situación de acumulación acelerada y mejora del bienestar social. 


\section{La evolución de la pobreza}

Aunque se carece de datos cuantilativos confiables, es probable que la política de estabilización y las medidas de ajuste hayan tenido un impacto diverso en la pobreza, según consideremos las diferentes calegorias de pobres.

a) Pobreza rural. Especialmente en el área rural, sigue siendo una verdad incontrovertible que la causa principal de la pobreza es la extrema desigualdad en la propiedad de los activos produclivos. De los aproximadamenle 1.400 .000 productores de granos básicos de Centroamérica, tan solo el $22 \%$ es capaz de generar algún excedente. 1.575 .000 productores de maíz cuentan con una superticie media de cultivo de 0.95 ha., lo cual explica la imposibilidad de aumenlar la productividad.

La reducción de los salarios reales de temporada en los cultivos de exportación, senalada anteriormente, junto a la reducción del número de empleos lemporales, ha seguido prolundizando la pobreza rural, que se ha traducido en diversos lugares, sobre todo en el Occidente del pais, por la emigración a la ciudad y el empleo en el servicio doméstico. De algún modo, podemos intuir un cierto cambio en los flujos migratorios, con una reducción parcial de la emigración desde el Oriente del país la que se debia a la situación de guerra en la zona- por un aumento relativo de la emigración desde el Occidente, por la crisis en los cullivos de exporlación. Esta siluación refleja el delerioro relativo de la situación de pobreza en el Occidente.

Por otro lado, el excedente agricola en los cultivos tradicionales ha desaparecido por causa de los bajos precios internacionales, y las ganancias solo se oblienen a costa del pago de unos salarios que se silúan por debajo del nivel de reproducción de la fuerza de trabajo. En lo que concieme a los cultivos no tradicionales, tenemos el caso de una cooperativa que exporta melones por valor de 300.000 dólares, y obliene un excedente de tan solo 45.000 colones. Son los comercializadores y distribuidores externos quienes se apropian de casi todo el excedente, quedando a los campesinos una renta que solo permite la reproducción simple.

b) La pobreza urbana. En este caso, se compnueba un cierto impacto de las medidas de compensación, que permiten avizorar una cierta contención de la pobreza absoluta. Por el contrario, los sectores que no han sido alcanzados por las políticas de compensación, ante el deterioro de los niveles de renta salariales, han visto deleriorarse su situación (pobreza relativa). En lodo caso, la reducclón de la pobreza masiva no ha 
sido un objetivo prioritario de las polílicas gubernamentales, cuyo impacto negalivo ha sido relalivamente más importanle en los seclores asalariados, formales e informales.

\section{Las propuestas alternativas: entre la modernización y la econo- mía popular}

En El Salvador la izquierda ha cambiado no solamente de métodos de lucha, sino de objelivos y estrategia. Los Acuerdos de Paz tenian tres componenles esenciales: la desmilitarización, la instilucionalización de un Estado de Derecho y la transferencia de tierras. Este último objetivo ha sido en la práctica el que con más insistencia y minuciosidad ha sido perseguido por el FMLN. La razón es doble: terminar la guerra sin una victoria, obligaba a compensar a quienes han mantenido las armas durante diez años. El énfasis en la transferencia de la tierra a los excombatientes refleja la base campesina del FMLN, pero este no ha planleado una relorma agraria: sobre un tolal de 1.452 .000 ha., de tierra en fincas, la reforma agraria contrainsurgente habia distribuido 334.895 ha., provenientes de las grandes propiedades de más de 500 ha. Por lo lanto, aunque su impacto lue limilado, significó una cierla redistribución, desde los grandes propietarios hacia los campesinos pobres. En el inventario de tierras negociado a raíz de los Acuerdos de Paz, el FMLN inventariaba 263.082 ha, pero el $82 \%$ de las propiedades eran de menos de 70 ha., y de las lierras estatales reclamadas (16.3\% de la superticie), una parte sustancial fueron asignadas a cooperativas de la relorma agraria o son propiedades embargadas por los bancos.

Por tanto, podemos concluir que el problema de la tierra sigue sin eslar delinitivamente solucionado en El Salvador, por cuanlo el peso de la gran propiedad sigue siendo determinante en la definición de las esIructuras sociales y económicas del agro. El $18 \%$ de tierras del inventario del FMLN contribuye sin embargo el capilal productivo con el que el FMLN cuenta inicialmenle para aplicar su proyecto.

Por otro lado, el FMNL ha dado un viraje suslancial respecto a las prácticas Iradicionales de la izquierda. EI FMLN ha reconocido, mucho antes que olras izquierdas latinoamericanas, que la nueva era del continente ha vuelto obsolelas no solo las estrategias de desarrollo tradicionales (agroexportación, industrialización suslituliva de importaciones) 0 las formas tradicionales de Estado (populismo, corporativismo, dictaduras militares) sino también las eslralegias reivindicativas propias de la izquierda. Ya no se tratarla de plantear un conjunto de exigencias al Estado y al capital, sino de hacer trente a la debilidad de las eslrucluras productivas desde una alternaliva que parta de la propia producción. El 
FMLN aspira a resolver el problema del cambio estruclural y de la pobreza comenzando no por el control del Estado, sino eslableciendo un espacio productivo controlado por la izquierda.

Esto planlea ciertos dilemas de estrategia económica: el FMLN ha nucleado su estrategia en el desarrollo de la producción rural, cuando el país se enfrenta a una crisis estructural de la producción agropecuaria de dimensiones históricas. Al mismo tiempo, carece de una estrategia económica nacional, con una gran debilidad en el desarrollo de alternativas para las áreas urbanas, donde se concentran las principales actividades económicas y recursos (Estado, industria, comercio, capilal financiero, servicios). Esla indelinición impide insertar el proyecto productivo en una estralegia global de desarrollo, quedando reducido a un proyeclo macroempresarial de perfiles aun bastante indefinidos y centrado en el sector menos dinámico de todos.

Además, no todos los sectores de "economía popular" están insertos en el proyecto del FMLN: sumadas las lierras de la Relorma Agraria y las del inventario, tenemos que más de un tercio del suelo ha pasado a manos de cooperalivas y de excombatientes. Por tanto, potencialmente nos encontramos ante un actor social nuevo, cuyo pertil requiere aun una clarificación polílica: mientras que la influencia sobre las cooperalivas de la retorma agraria sigue siendo lundamentalmente democratacrisliana, el FMLN viene a intentar aplicar un proyecto que deberá incluir esle sector. Desde el punto de vista inslitucional, ya ha avanzado esta influencia, pues las organizaciones cooperativas más importantes (CONFRAS y FESACORA-COACES) están fuertemente inspiradas por el FMLN, to cual significa un signilicalivo avance de la izquierda en el sector.

Pero también la derecha presenta su proyecto a los sectores más pobres: a través de las instituciones gubernamentales de la relorma agraria (FINATA e ISTA) el gobierno apuesta por la parcelización de las cooperalivas, apoyándose en la tradicional aspiración del campesino a la propiedad, y con una luerte campana propagandíslica de desligitimación de los derechos a la propiedad del sistema cooperativo, y su ahogamienlo en materia de concesión de créditos y asistencia técnica e infraestructuras. Por su parte, la AID está potenciando determinadas alternativas a los proyectos de desarrollo impulsados por el FMLN. Apoyándose fundamenlalmente en la orden salesiana, está tinanciado suslanciosamente a la ciudadela Don Bosco, la Universidad Don Bosco, el Poligono Industrial Don Bosco y lambién a la fudación Agape (que tiene ol estatuto jurldico de recinto fiscal exportador-maquila), para implantar proyectos "politicamente" controlados en las zonas de influencia 
de la izquierda (especialmente el norte de Chalatenango y Morazán). Un esfuerzo que podemos calificar de "contrainsurgencia económica"" que aprovecha los vacios más significativos del proyeclo de la izquierda, especialmente la alternativa industrial-urbana.

Por úllimo, el fracaso del programa de estabilización y ajuste sin cosle social -fracaso en términos de desarrollo económico, aunque notable éxilo en términos de recomposición de los mecanismos de acumulación de los sectores hegemónicos del capital-se encuentra sin alternaliva explicita por parte de las fuerzas de oposición, y en primer lugar de quienes impulsan un proyecto alternativo. A esio contribuye sin duda la limitada comprensión de los alcances esiruclurales de las políticas macroeconómicas, cuya discusión suele establecerse en un marco academicista y tecnocrático. Pero creemos que lo apuntado en este articulo será suficiente para entender porqué la lucha política lendrá en los próximos afios un fuerte contenido económico-productivo.

Formaclón bruta de capltal fljo en El Salvador1970-1991

\begin{tabular}{|ccrcc|}
\hline Año & FBCF/'PIB & Ipri/PIB & Ipub/PIB & Ipriv/lpub \\
\hline 1970 & 10.7 & 8.4 & 2.3 & 78.5 \\
1971 & 11.2 & 8.3 & 2.9 & 74.1 \\
1972 & 14.1 & 10.1 & 4 & 71.6 \\
1973 & 12.4 & 8.8 & 3.6 & 71.0 \\
1974 & 14.2 & 9.5 & 4.7 & 66.9 \\
1975 & 23 & 15 & 8 & 65.2 \\
1976 & 20.1 & 13.9 & 6.2 & 69.2 \\
1977 & 21.2 & 13.9 & 5.8 & 65.6 \\
1978 & 21.4 & 15.6 & 6.1 & 72.9 \\
1979 & 17.5 & 11.5 & 4.6 & 65.3 \\
1980 & 13.5 & 6.4 & 7.1 & 47.4 \\
1981 & 13.5 & 6.2 & 7.3 & 45.9 \\
1982 & 12.6 & 6.5 & 6.1 & 52.6 \\
1983 & 11.6 & 7 & 4.6 & 60.3 \\
1984 & 11.5 & 7.6 & 3.9 & 66.1 \\
1985 & 12 & 9.7 & 3.3 & 72.5 \\
1986 & 13.1 & 10.6 & 2.5 & 80.9 \\
1987 & 13.6 & 10.7 & 2.9 & 78.7 \\
1988 & 12.5 & 9.5 & 3 & 76.0 \\
1989 & 12.9 & 10 & 2.9 & 77.5 \\
1990 & 11.8 & 9.5 & 2.3 & 80.5 \\
1991 & 13.8 & 10.9 & 2.9 & 79.1 \\
1992 & 15.1 & 11.7 & 3.3 & 77.5 \\
\hline
\end{tabular}

Fuente: Banco Mundial y GOES (1992). 
Plan de reconstrucción nacional. Fase de contingencla.

Programa o proyectos de jecuclón (millones de colones)

Monlo invertiido: 158.7

Unidades ejecutoras: GOES (2-0.9); Alcaldías (66.6) ONG'S (71.2).

Proyeclo en ejecución 281.5

Infraestructura básica: 71.2

Desarrollo integral:

31.7

Información y apoyo interinstitucional:

Apoyo a acuerdos de paz: 166.6

Reinserción de desmovilizados:

37.5

Apoyo económico agropecuario:

Apoyo adquisición de tierras:

2.2

Apoyo económico no agropecuario:

13.1

Rehabilitación de lisiados:

22.8

Otros programas:

Fuente: GOES, SRN, Diciembre 1992.

Evoluclón de crédito y de los depósitos bancarlos, 1987-1992 (Millones de colones)

\begin{tabular}{|c|c|c|c|c|c|c|}
\hline & 1987 & 1988 & 1989 & 1990 & 1991 & Junio/92 \\
\hline Crédilo privado & 5528.5 & 6218.4 & 6884.9 & 7494.3 & 8701 & 9758.2 \\
\hline Crédito público & 3835.3 & 4245.2 & 5209 & 6082.1 & 7055.2 & 6789.3 \\
\hline $\begin{array}{l}\text { Crédito tolal } \\
\text { Cuenta }\end{array}$ & 9363.8 & 10463.6 & 12093.9 & 13576.4 & 15756.2 & 16547.5 \\
\hline corrientes & 1514.3 & 1706.8 & 1657.7 & 2333 & 2429 & 2933.4 \\
\hline $\begin{array}{l}\text { Cuentas de } \\
\text { ahorro y plazo }\end{array}$ & 4873.2 & 5560.7 & 6066.7 & 8200.5 & 10069.7 & 11019.2 \\
\hline $\begin{array}{l}\text { Depósitos } \\
\text { Totales }\end{array}$ & 6387.5 & 7267.5 & 7724.4 & 10541.5 & 12498.7 & 13952.6 \\
\hline CT/DT & 1.47 & 1.44 & 1.57 & 12.9 & 1.26 & 1.19 \\
\hline C.priv/DT & 0.87 & 0.86 & 0.89 & 0.71 & 0.70 & 0.70 \\
\hline c. pub./DT & 0.60 & 0.58 & 0.67 & 0.58 & 0.56 & 0.49 \\
\hline
\end{tabular}

Fuente: Elaboración propia sobre dalos del BCR 
Balanza comerclal de El Salvador

(Millones de dolares)

\begin{tabular}{cccc}
\hline & $\begin{array}{c}\text { Exportaciones } \\
\text { FOB }\end{array}$ & $\begin{array}{c}\text { Importaciones } \\
\text { CIF }\end{array}$ & $\begin{array}{c}\text { Termnos de } \\
\text { inlercambio* } \\
\text { (base 1987) }\end{array}$ \\
\hline 1987 & 590 & 994 &. .0 \\
1988 & 610 & 1007 & +2.0 \\
1989 & 498 & 1161 & -14.0 \\
1990 & 582 & 1262 & -30.3 \\
1991 & 588 & 1406 & n.d. \\
1992 & 584 & 1613 & . \\
\hline
\end{tabular}

- Indice de variación del valor unitario de las exportaciones menos el índice de variación del valor unitario de las importaciones.

Fuente: Elaboración propia a partir de dalos del BCA.

\section{Gobierno central: Ingresos y gaslos corrlentes} (millones de colones)

\begin{tabular}{|c|c|c|c|c|}
\hline & $\begin{array}{l}\text { Ingfreso } \\
\text { corriente }\end{array}$ & $\begin{array}{l}\text { Gasto } \\
\text { corriente }\end{array}$ & Ahorro & $\begin{array}{c}\text { Ahorro/I } \\
\text { Corr. (\%) }\end{array}$ \\
\hline 1976 & 816.0 & 563.0 & 252.5 & 30.9 \\
\hline 1977 & 1178.3 & 681.4 & 496.9 & 42.2 \\
\hline 1978 & 1013.3 & 833.6 & 179.7 & 17.7 \\
\hline 1979 & 1192.0 & 901.6 & 290.4 & 24.4 \\
\hline 1980 & 1014.5 & 1104.2 & -89.7 & -8.8 \\
\hline 1981 & 1090.0 & 1239.1 & -149.1 & -13.7 \\
\hline 1982 & 1108.7 & 1311.8 & -203.1 & -18.3 \\
\hline 1983 & 1256.5 & 1507.0 & -250.5 & -19.9 \\
\hline 1984 & 1537.5 & 1770.4 & -232.9 & -15.1 \\
\hline 1985 & 1921.2 & 1908.9 & 12.3 & 0.6 \\
\hline 1986 & 2845.9 & 2567.2 & 278.7 & 9.8 \\
\hline 1987 & 2760.5 & 2761.8 & $-\quad 1.3$ & 0.0 \\
\hline 1988 & 2843.8 & 3042.2 & -198.4 & -7.0 \\
\hline 1989 & 2659.9 & 3398.4 & -738.5 & -27.8 \\
\hline 1990 & 3367.0 & 3684.6 & -317.6 & -9.4 \\
\hline 191 & 4362.9 & 4690.6 & -327.7 & -7.5 \\
\hline
\end{tabular}

Fuente: Elaboración propia sobre dalos del BCA 